Saudi Journal of Biomedical Research

Abbreviated Key Title: Saudi J Biomed Res ISSN 2518-3214 (Print) |ISSN 2518-3222 (Online) Scholars Middle East Publishers, Dubai, United Arab Emirates Journal homepage: https://saudijournals.com

\title{
Prevalence of Pseudoexfoliation (PEX) Syndrome in Patients in East Libya: Hospital-based Study
}

\author{
${ }^{1}$ Lecturer, Ophthalmology department, Omar Almukhtar University Libya \\ ${ }^{2}$ Ophthalmology department, Benghazi University Libya \\ ${ }^{3}$ Assistant professor, ophthalmology department, Benghazi University Libya
}

Bahjah Abdulhamid Hamad Esehiyb ${ }^{1 *}$, Prof. Anwer Gebril Eldursi² ${ }^{2}$ Mariam M.B. Gebril ${ }^{3}$

DOI: $10.36348 /$ sjbr.2021.v06i02.004

| Received: 20.01.2021 | Accepted: 01.02.2021 | Published: 11.02.2021

*Corresponding author: Bahjah Abdulhamid Hamad Esehiyb

\section{Abstract}

PEX is a systemic disease with ocular manifestations represented by deposition of white fibrillogranular material on the internal tissue of the eye. It is an age related and environmentally influenced disorder of the elastic fibre structure. Pseudo exfoliation is present worldwide in every race and ethnic group with variable prevalence. Methods: A retrospective descriptive study of records of 398 patients, scheduled for cataract surgery in the martyr Sohail Alatrash eye hospitalBenghazi from 1-Januray-2010 to 31-May -2010, were included. Demographic parameters like age and sex as well as clinical Features including the presence of PEX were collected. Results: Out of 398 patients enrolled, 56 were diagnosed with PEX. A statistically insignificant relationship was found between PEX and advancing age in both males and females $(P>0.005)$. Conclusion: We found the prevalence of PEX syndrome among Libyans patients with age -related cataract scheduled for surgery aged 40 years or older to be $14.1 \%$.

Keywords: Pseudoexfoliation, PEX, Libyans patients, males and females.

Copyright (C) 2021 The Author(s): This is an open-access article distributed under the terms of the Creative Commons Attribution 4.0 International License (CC BY-NC 4.0) which permits unrestricted use, distribution, and reproduction in any medium for non-commercial use provided the original author and source are credited.

\section{INTRODUCTION}

Pseudoexfoliation (PEX) syndrome is a disease known for more than a century when it was described by John Lindberg in 1917 in his doctoral thesis [1]

PEX is a systemic disease with ocular manifestations represented by deposition of white fibrillogranular material on the lens capsule and zonules, ciliary body, pupillary margin, corneal endothelium, and trabecular meshwork [2].

Beside its systemic manifestation in skin and visceral organs it is associated with an increasing number of vascular disorders, hearing loss and Alzheimer disease [3]. It is an age related and environmentally influenced disorder of the elastic fibre structure [4], it is rarely seen in persons younger than 50 years and it is occurs most commonly in individuals as older than 70 years [5].

Pseudoexfoliation syndrome is generally asymptomatic and diagnosed incidentally on examination but it is associated with increased incidence of age-related cataract and open angle glaucoma [6]

Also, intraoperative complications as zonular weakness and poor pupillary dilation, posterior capsule rupture and vitreous loss during cataract extraction in PEX eyes is more in compared to normal eyes, leading to a poor visual outcome [7].

Pseudoexfoliation syndrome is more common in females but males appear to be at higher risk of developing open angle glaucoma [4].

Pseudo exfoliation is present worldwide in every single race and ethnic group with variable prevalence. The reported prevalence of PEX rates varies extensively from $0 \%$ to more than $40 \%$ [8].

AIM

To study the prevalence of Pseudoexfoliation syndrome (PEX) among Libyan patients attending the martyr Sohail Alatrash eye hospital - Benghazi in east of Libya with age-related cataract scheduled for surgery. 


\section{PATIENTS AND METHODS}

A retrospective descriptive study of a total of 796 eyes of 398 patients, scheduled for cataract surgery in the martyr Sohail Alatrash eye hospital- Benghazi from 1-Januray-2010 to 31-May -2010, were included. Demographic parameters like age and sex as well as clinical Features including the presence of PEX were collected.

All eyes underwent complete eye examination and were evaluated for the signs of pseudoexfoliation material in the pupil, iris, and lens capsule on dilated slit lamp examination.

Inclusion criteria included patients that were above the age of 40 years with age-related cataract and scheduled for cataract surgery without prior history of intraocular surgery in the examined eye. Cataract cases secondary to systemic diseases, uveitis, corneal opacity, and trauma were excluded.

The presence of PEX was confirmed by looking for the typical fluffy, white granular material at the pupillary margin, anterior capsular lens surface and surface of the iris.

The population of the study was then divided into two groups: the PEX group and the non-PEX group. The gathered data was then analyzed and relevant comparisons between the two groups were made.

The type of lens opacity and preoperative IOP (using a Goldmann applanation tonometer) were gathered and recorded on the total population of the study

Statistical analyses were performed using IBM SPSS version 20.0 (SPSS v.20.0, Illinois, USA). Comparisons between the two groups were calculated using the Pearson chi-square test. The frequency analysis was done by chi-square testing. $\mathrm{P}<0.05$ was considered statistically significant.

\section{RESULTS}

A total of 398 consecutive patients (males: 167, females: 231) aged 40-90 years were included in this study, out of 398 patients enrolled, 56 were diagnosed with PEX.

The mean age was $(64.8 \pm 8.85)$ years. PEX was found in $14.1 \%$ (56 patients) with a male to female ratio of 1:1.1 (females: 34 (14.7\%), males: 22(13.2\%).

The mean age of the patients with PEX $(68.7 \pm$ 7.45 years) and was higher than that of those without PEX (64.1 \pm 8.90 years). It was statistically significant $(\mathrm{P}=0.000)$. The study demonstrated that the prevalence was $0.00 \%$ in (40-49) the age group, increasing to $4.5 \%$ in(50-59) age group , $14.2 \%$ in (60-69) age group, $19 \%$ in (70-79) age group and $25.9 \%$ in 80 and above age group.

Table (1) shows the relationship between PEX and age, and gender. A statistically insignificant relationship was found between PEX and advancing age in both males and females $(P>0.005)$.

Table-1: Age and gender distribution of the study group

\begin{tabular}{|l|l|l|l|l|l|}
\hline Age group & $\begin{array}{l}\text { No of males } \\
\text { enrolled }\end{array}$ & $\begin{array}{l}\text { No of male } \\
\text { PEX patients } \\
\text { \% }\end{array}$ & $\begin{array}{l}\text { No of } \\
\text { females } \\
\text { enrolled }\end{array}$ & $\begin{array}{l}\text { No of female } \\
\text { PEX patients } \\
\text { \% }\end{array}$ & p-value* \\
\hline $40-49$ & 10 & - & 10 & - & - \\
\hline $50-59$ & 27 & $1(3.7 \%)$ & 39 & $2(5.1 \%)$ & $>0.05$ \\
\hline $60-69$ & 79 & $9(11.4 \%)$ & 90 & $15(16.7 \%)$ & $>0.05$ \\
\hline $70-79$ & 37 & $8(21.6 \%)$ & 79 & $14(17.7 \%)$ & $>0.05$ \\
\hline 80 and above & 14 & $4(28.6 \%)$ & 13 & $3(23.1 \%)$ & $>0.05$ \\
\hline Total & 167 & $22(13.2 \%)$ & 231 & $34(14.7 \%)$ & $>0.05$ \\
\hline
\end{tabular}

*Chi Square test.

For calculation of mean IOP, only one eye of each person was considered. In people with unilateral PEX, the eye with PEX was considered. In those with bilateral PEX and in the population without PEX, one eye was chosen at random.

The mean IOP in people with PEX was 15.75 $\mathrm{mmHg} \pm 4.17$. (95\% confidence interval (CI), (14.63 to16.86) and without PEX was $13.46 \mathrm{mmHg} \pm 3.9$ (95\% $\mathrm{CI},(13.04$ to 13.87$)$ respectively the difference was significant $(\mathrm{P}=0.000)$.

Mature cataract was the dominant lens opacity in all groups $31.4 \%$, followed by posterior sub-capsular cataract $27 \%$, mixed 23.4\%, nuclear $12.56 \%$, cortical $2.5 \%$, hypermature $2 \%$, posterior polar $0.5 \%$, intumescent $0.25 \%$.

In both groups mature cataract was the dominant lens opacity with a higher frequency in the PEX group compared to the non-PEX group (33.9\% and $31 \%$, respectively $) \quad(\mathrm{p}=0.938$ statistically insignificant).

\section{DISCUSSION}

The reported prevalence rate of PEX syndrome in various populations shows broad variations. 
In a hospital-based study done in Jordan, the prevalence of pseudoexfoliation in patients aged 40-90 years was $9.1 \%$. In another study from Yemen the prevalence of PEX in patients undergoing cataract surgery was $19.53 \%[9,10]$. While the prevalence of PEX in Egypt is $4.14 \%$ [11].

However, this percentage was higher in other series: PEX was $40.9 \%$ in patients preparing for cataract surgery in Somalia [12] and39.3\% in Ethiopia [13]. To the best of our knowledge, there are no previous reports on the prevalence or characteristics of PEX in Libya; the prevalence of pseudoexfoliation among individuals aged 40 years or older in this study was $14.1 \%$.

One of the limitations of this study is being a hospital based rather than a population-based study, over or under-estimation of the prevalence of PEX and or co-morbidities associated with PEX may be attributed to the hospital-based nature of the study.

According to this study the results showed $0.0 \%$ of PEX in Libyan below the age of 50 years. The frequency of PEX age dependently increased to $25.9 \%$ in the subjects above the age of 80 years.

Our results are consistent with other study on Saudi population [14] and neighbouring Egypt [11] who also observed a similar increasing pattern of PEX with aging.

In addition, the findings revealed that the mean age of subjects with PEX syndrome was (4.6) years older than the normal population. Considering age specific prevalence rates, there was significant linear increase in prevalence with age; these findings are similar to those of other studies [15].

The mean age of the PEX group was significantly higher than the non-PEX group. This was demonstrated also by reports that evaluated the prevalence of PEX in a similar population like ours, patients scheduled for cataract surgery [16].

The results further indicated that there was no significant difference between male and female frequency of PEX, the prevalence of PEX among males was $13.2 \%$ as compared to $14.7 \%$ in females (with a male to female ratio of $1: 1.1$ ); a similar finding was reported in the prevalence of PEX among patients undergoing cataract Surgery in and Riyadh, Saudi Arabia [14] and Ethiopia [13]. Regarding the results of our study, the mean IOP in subjects with PEX was $(2.3 \mathrm{mmHg})$ higher than in those without PEX.

This difference was significant. This is supported by many reports in literature $[17,18]$. The most common cataract type in our PEX and non PEX patients was mature cataract group with a higher frequency in the PEX group (33.9\% and 31\%, respectively). In contrast, previous studies reported nuclear cataract as the most cataracts is often more frequently found in eyes with PEX than in eyes without it, and others reported a higher rate of a subcapsular cataract [10]. Reason for this discrepancy might be explained by shortage of cataract surgery facility and long waiting list for cataract surgery in east of Libya as it is available only at the martyr Sohail Alatrash eye hospital- Benghazi.

\section{CONCLUSION}

This observed study attempted to drop light on prevalence of Pseudoexfoliation syndrome in east of Libya. We found the prevalence of PEX syndrome among Libyans patients with age -related cataract scheduled for surgery to be $14.1 \%$ which means it's slightly common in east Libya, and its increases with advancing age.

Intraocular pressure (IOP) in eyes with PEX syndrome higher than eyes with out. Mature cataract was the dominant lens opacity in both groups.

\section{REFERENCES}

1. Tarkkanen, A., \& Kivelä, T. (2002). John G. Lindberg and the discovery of exfoliation syndrome. Acta Ophthalmologica Scandinavica, 80(2), 151-154.

2. Schlötzer-Schrehardt, U., \& Naumann, G. O. (2006). Ocular and systemic pseudoexfoliation syndrome. American journal of ophthalmology, 141(5), 921-937.

3. Kanski, J.J., Bowling, B., Nischal, K.K., Pearson, A. (2011). Glaucoma. In: clinical ophthalmology: A systematic approach, 7th edition Edinburgh: Butterworth Heinmann Elsevier; 355.

4. Schöltzer-Schrehardt, U. (2012). Pseudoexfoliation syndrome: the puzzle continues. J Ophthalmic Vis Res, 7(3):187-189.

5. Cioffi, G.A., Durcan, F.J., \& Girkin, C.A.G. (2011). Open Angle Glaucoma.in:G.L.Skuta, L.B.Cantor, J.S, Weiss (Eds.) Basic and clinical science course (BCSC) section 10: Glaucoma. American Academy of Ophtlalmology (AAO), San Francisco(CA), 104.

6. Ritch, R., Schlötzer-Schrehardt, U. (2001). Exfoliation Syndrome. Surv Ophthalmol 2001; 45: 265-315.

7. Dwivedi NR, Dubey AK, Shankar PR. Intraoperative and Immediate Postoperative Outcomes of Cataract Surgery using Phacoemulsification in Eyes with and without Pseudoexfoliation Syndrome. J Clin Diagn Res. 2014;8(12):VC01-VC05.

8. Rashid, W., Lone, I. A., Latiff, M., \& Qureshi, S. T. (2015). Pseudoexfoliation syndrome in Kashmiri patients scheduled for cataract surgery. Journal of 
Evolution of Medical and Dental Sciences, 4(5), 853-862.

9. Shihadeh, W. A., Jammal, H. M., Alkhatib, S. Q., Okour, F. M., Gharaibeh, A. M., Alqudah, N. M., \& Alqudah, A. A. (2012). Prevalence of Exfoliation Syndrome in Patients Scheduled for Cataract Surgery: A Hospital-based Study in Northern Jordan. Jordan Med J, 46(3), 216-20.

10. Al-Shaer, M., Bamashmus, M., \& Al-Barrag, A. (2010). Point prevalence of pseudoexfoliation syndrome in patients scheduled for cataract surgery in eye camps in Yemen. Middle East African journal of ophthalmology, 17(1), 74.

11. Shazly, T. A., Farrag, A. N., Kamel, A., \& AlHussaini, A. K. (2011). Prevalence of pseudoexfoliation syndrome and pseudoexfoliation glaucoma in Upper Egypt. BMC ophthalmology, 11(1), 1-6.

12. Kalayc1, M. (2020). Pseudoexfoliation Syndrome Prevalence in Somali Patients with Senile Cataract. Istanbul Medical Journal= Istanbul Tip Dergisi, 21(5), 380.

13. Teshome, T., \& Regassa, K. (2004). Prevalence of pseudoexfoliation syndrome in Ethiopian patients scheduled for cataract surgery. Acta Ophthalmologica Scandinavica, 82(3p1), 254-258.
14. Al-Saleh, S. A., Al-Dabbagh, N. M., Al-Shamrani, S. M., Khan, N. M., Arfin, M., Tariq, M., \& AlFaleh, H. M. (2015). Prevalence of ocular pseudoexfoliation syndrome and associated complications in Riyadh, Saudi Arabia. Saudi medical journal, 36(1), 108.

15. Henry, J. C., Krupin, T., Schmitt, M., Lauffer, J., Miller, E., Ewing, M. Q., \& Scheie, H. G. (1987). Long-term follow-up of pseudoexfoliation and the development of elevated intraocular pressure. Ophthalmology, 94(5), 545-552.

16. Olawoye, O. O., Pasquale, L. R., \& Ritch, R. (2014). Exfoliation syndrome in sub-Saharan Africa. International ophthalmology, 34(5), 1165 1173.

17. Kaljurand, K., \& Puska, P. (2004). Exfoliation syndrome in Estonian patients scheduled for cataract surgery. Acta Ophthalmologica Scandinavica, 82(3p1), 259-263.

18. Kozobolis, V. P., Papatzanaki, M., Vlachonikolis, I. G., Pallikaris, I. G., \& Tsambarlakis, I. G. (1997). Epidemiology of pseudoexfoliation in the island of Crete (Greece). Acta Ophthalmologica Scandinavica, 75(6), 726-729. 